
\title{
Besearch S Surare \\ Emergy Based Ecological Efficiency Evaluation and Optimization Method for Logistics Park
}

Cui Wang ( $\square$ wangcui@ahszu.edu.cn )

Suzhou University https://orcid.org/0000-0003-0339-0940

Cuixia Zhang

Suzhou University

Fagang Hu

Suzhou University

Yuan Wang

Suzhou University

Li'e Yu

Suzhou University

Conghu Liu

Suzhou University

\section{Research Article}

Keywords: emergy, logistics park, ecological efficiency, evaluation, optimization

Posted Date: April 23rd, 2021

DOI: https://doi.org/10.21203/rs.3.rs-424428/v1

License: (c) (i) This work is licensed under a Creative Commons Attribution 4.0 International License.

Read Full License 


\title{
1 Emergy based ecological efficiency evaluation and optimization
}

\section{2 method for Logistics Park}

3 Cui Wang 1,2, ${ }^{\text {, }}$ Cuixia Zhang ${ }^{3}$, Fagang Hu ${ }^{1}$, Yuan Wang ${ }^{1,2}$, Li'e $\mathrm{Yu}^{1}$ and Conghu Liu ${ }^{3,4}$

1 Business School, Suzhou University, Suzhou 234000, China; hufg@ahszu.edu.cn (F.H.); wangyuan151617@163.com (Y.W.); yulie@ahszu.edu.cn (L.Y.);

2 Center for International Education, Philippine Christian University, 1004 Manila, Philippines

3 College of mechanical and Electronic Engineering, Suzhou 234000, China; cuixiazhang@126.com (C.Z.); 1ch339@126.com (C.L.)

4 School of economics and management, Tsinghua University, Beijing, 100084 China

* Correspondence: wangcui@ahszu.edu.cn (C. W.)

\begin{abstract}
The rapid development of the economy and the change in transaction mode has promoted the development of logistics parks. How to evaluate and optimize the ecological efficiency of logistics park to achieve its sustainable development has been considered a challenge. Therefore, this paper puts forward an emergy based ecological efficiency evaluation and optimization method for Logistics Park. By constructing the ecological efficiency evaluation model of logistics park, it quantitatively evaluates the ecological efficiency and sustainable development of logistics park, and analyzes the correlation between various factors and ecological efficiency. The application results of H Logistics Park show that fuel oil, information technology, net profit, and waste gas are closely related to the ecological efficiency of logistics park, and the correlation coefficients are $0.8248,-0.6949,0.8544$ and 0.7661 respectively. On this basis, the paper puts forward some suggestions to improve the ecological efficiency of the logistics park. This paper provides theoretical and methodological support for the evaluation and optimization of the ecological efficiency of the logistics park.
\end{abstract}

Keyword: emergy, logistics park, ecological efficiency, evaluation, optimization

\section{Introduction}

With the rapid development of the global economy and information technology, the process of industrialization and urbanization is accelerating, which leads to the increasingly prominent contradiction between economic growth and the environment (Zhai et al.2020; Tian G et al. 2019). The arbitrary exploitation of natural resources and the free use of the environment have caused global ecological damage, resource shortage, waste (Geng et al.2021), environmental pollution (Cai et al.2018), and other major problems, which have seriously affected economic development and quality of life.

As a product of the development of the logistics industry, the logistics park is an important carrier of the logistics industry cluster development (Sun et al.2017). Through the intensive management of logistics resources, it can improve logistics efficiency and reduce logistics cost, which is of great significance to improve the logistics development environment and improve logistics efficiency (Xu et al.2018). However, the development process of the logistics park also has a certain degree of negative effect on resources and the environment (Makarov et al.2019). For example, the market demand was not scientifically analyzed in the early stage, and the function positioning was not clear (Li et al.2020), 
which made the construction of the logistics park inconsistent with the actual needs of enterprises, resulting in the vacancy of the park, low utilization rate of land and equipment in the logistics park, and the lack of reuse of waste generated in the logistics process of the park. In the global sustainable development environment, how to distinguish the current situation of the ecological development of logistics park, identify and improve the adverse ecological factors, guide the logistics park to pay attention to the ecological and social environment to make the logistics park become an economic subject that can adapt to the harmonious development of economy, society, and environment, and promote its sustainable and healthy development is an imperative research topic.

To achieve the above research objectives, this paper is arranged as follows. In the second part, the relevant literature on ecological efficiency is provided and the significance of this paper is expounded. The third part introduces the scope, process of ecological efficiency, ecological efficiency model, and optimizing decision making. The fourth part is a case study to verify the feasibility and effectiveness of the method. The fifth part is the conclusion.

\section{Literature review}

With the rapid development of the economy, the relationship between the environment and economy is particularly prominent. Sustainable development has become the theme of today's social development, the concept of eco-efficiency has attracted the attention of scholars. The concept of eco-efficiency was first put forward by German scholars Schaltegger and Sturn in 1990. It is used to describe the utilization rate of ecological resources to meet human survival. It is defined as the ratio of energy load of resources consumed by enterprise production or economy to the value of products and services (Schaltegger and Burritt.2000). In 1992, the World Federation of Sustainable Development Industry and Commerce (WBCSD) considered that eco-efficiency requires not only to provide goods and services to meet the needs of human life in the whole life cycle of goods and services but also to reduce the impact on the ecological environment and resource consumption (Schmidheiny.1992). In 1998, the World Economic Cooperation Organization (OECD) put forward the concept of eco-efficiency, which greatly expanded the application scope and level of ecological efficiency, and promoted research on how to invest resources into industries to maximize added value and reduce resource consumption (Sturm et al.2004).

The research on eco-efficiency has focused mainly on the evaluation index system and evaluation method. A large number of wastes is produced in the industrial production process and thus, the eco-efficiency evaluation is more applied to the sustainability evaluation of the manufacturing industry and industrial parks (May et al.2019; Shao et al.2019). Life cycle assessment is often used to evaluate the eco-efficiency of manufacturing processes (Alfredo et al. 2017; Nuri et al.2019; Leonardo et al. 2020). A similarity model of an intuitionistic fuzzy set is established to conduct the intuitionistic fuzzy 
identification of the enterprise eco-efficiency influencing factors and taking a large-scale oil refining and chemical company for application testing (Zhang et al.2019). Aligned with the concepts and principles of sustainable development, the eco-efficiency comparison index is developed and applied to evaluate a petrochemical facility in real-time (Pereira et al.2019). Considering three linked but independent subsystems of the economy - society - environment cyclic system, an improved matrix-type network data envelopment analysis model with undesirable output was developed to evaluate the eco-efficiency of China's 30 provinces (Yu et al.2019). An ESV-based eco-efficiency evaluation index system was established for evaluating the ecological performance of an industrial park and has been used by decision-makers for sustainable landscape planning and development (Shi et al.2017). Considering that eco-industrial parks are a complex system, Wang et al. used the grey relational analysis method to evaluate the eco-efficiency of coupling and symbiosis networks in an eco-industrial park in oil and gas resource-based cities (2019). Data envelopment analysis was used to evaluate eco-efficiency and optimal levels of fertilizer use based on the social cost and social benefits in tea production (Shamsheer et al.2019). The logistics industry also hopes to achieve sustainability through eco-efficiency evaluation and integration of eco-innovation initiatives. For the multi-objective linear problem with three objectives: minimize costs, cumulative energy demand, and waste in a reverse logistics network, a two-phased heuristic is proposed to assess eco-efficiency in logistics networks (Quariguasi et al.2017). Wang et al. analyzed the effects of China's trade with economies participating in the Belt and Road Initiative on the ecological total factor energy efficiency of China's logistics industry from the perspective of ecological economics, and identify its relative role in China's trade with other regions (2020). A carbon-constrained stochastic model for eco-efficient reverse logistics network is designed under environmental regulations in the CRD industry and addresses a two-stage stochastic model for eco-efficient reverse logistics network design (Trochu et al.2017). Long et al. proposed combining a super slack-based measure data envelopment analysis model and the global Malmquist index to evaluate the logistics ecological efficiency and used global and local Moran's indices to analyze the spatial autocorrelation of logistics ecological efficiency, a spatial econometric model is proposed to study how the influencing factors interference affect logistics ecological efficiency (2020). Data envelopment analysis is applied to derive an efficiency score that reflects the degree to which sustainable operational logistics performance is achieved within each sample nation (Kamran and Kevin 2019). The method based on hybrid numerical decision-making was used to evaluate the intelligent logistics eco-index, and then the possibility decision matrix was established and the ILEI based on the sorting theory of fuzzy complementary judgment matrix was calculated (Liu et al.2020). The challenges to implementing eco-innovation practices for freight logistics sustainability are identified, using the best-worst method to evaluate and rank the challenges, aiding management to make informed decisions to overcome these challenges before the environmental burdens become 
critical (Ifeyinwa et al.2019). The performance of the Louisiana freight network under three different scenarios is evaluated, the benefits of mode changes evaluating the tradeoff between environmental goals and other performance measures are measured by Kelle et al. (2019). A set of sustainability indicators for urban freight transport is proposed by Liu, and fuzzy logic is used to develop a sustainable index for urban freight transport (Bandeira et al.2018). Melkonyan et al. develops a toolset for exploring the sustainability potential of last-mile logistics and distribution strategies, a system dynamics (SD) simulation, and a multi-criteria decision aid (MCDA) were applied to assess the sustainability performance of these distribution channel options (2020).

Although many scholars have studied the ecological efficiency, these studies have the following shortcomings. (i)In the process of evaluation, the dimensions of various flows (material flow, energy flow and economic flow) in the system are different, so it is impossible to sum up or compare, and it is impossible to organically combine nature, economy and society, so it is impossible to objectively evaluate the ecological efficiency. (ii)The role and contribution of natural ecological environment to human economic and social development, as well as the reuse and recycling of wastes or by-products, are not fully considered, and the input and consumption of economically valuable resources and environment are ignored.

Therefore, it is a difficult problem for economists, ecologists and other scholars to adopt a unified measurement standard to solve the unified problem of quantitative evaluation of natural environment resources and human economic activities. An American ecologist, H.T. Odum, first proposed the emergy theory, from the perspective of system ecology, taking the solar energy value as the basic measurement unit, converted different kinds of energy in ecosystem and socio-economic system into solar energy value to measure and analyze, and studied the relationship between ecological environment and human activities from the perspective of solar energy (1996). This method has the following advantages. (i) It overcomes the disadvantages of subjectivity of ecological efficiency evaluation method, and solves the problem of the connection of material flow, energy flow and economic flow, and can directly calculate the real value of the system. (ii) For eco economic system, emergy method can reflect the interaction and contribution among social, economic and natural subsystems. (iii) This method unifies the ecosystem and human social economic system, helps to adjust the relationship between ecological environment and economic development, and provides an important measurement standard for human understanding of the world.

Emergy theory is widely used in the study of various natural ecosystems. An emergy-based evaluation and improvement for sustainable manufacturing systems considering resource efficiency and environmental performance was conducted by Liu (2018). An emergy-based sustainability evaluation of remanufacturing machining systems was conducted by Liu (2018) and an integrated optimization control method for remanufacturing assembly system was proposed (Liu et al.2019). An emergy-based 
metal production evaluation framework is proposed by Pan et al., taking a life cycle perspective from the formation of mineral deposit to the final production of metal (2019). Cai et al. proposed an emergy-based sustainability evaluation method for outsourcing machining resources for improving resource utilization efficiency (2020). By using an emergy-based integrated approach, the trends of environmental sustainability of this sector during the 2005-2015 periods investigated (Shen et al.2019). Fan and Fang using the energy based ecological footprint method to study the actual impact of all the resources including water resources and non-renewable resources on the environment (2020). Logistics park have a similar organization and operation mode with industrial park. Therefore, the emergy theory can be applied to the analysis of eco economic system and the quantitative analysis and evaluation of the sustainability of the logistics park. The emergy synthesis method is used to analyze the logistics network, and the environmental costs and benefits of the logistics system are evaluated and compared from the perspective of distributors and steel plant operators (Biagio et al.2013). The emergy based evaluation method for sustainable development of logistics park is constructed to improve the sustainable development ability of logistics park (Wang et al.2020).

Based on the collection, collation, and analysis of logistics enterprise efficiency evaluation literature, combined with the current development of logistics park, this paper conducts a unified dimension processing of the collected relevant data from the perspective of emergy, constructs an evaluation model of logistics park eco-efficiency, analyzes the correlation between various factors and eco-efficiency, and takes Logistics Park $\mathrm{H}$ as an example to verify the feasibility of the evaluation model in practice. Finally, the conclusion is formed, and the suggestions of eco-efficiency optimization based on emergy are put forward.

In theory, from the perspective of emergy, this paper defines the boundary and scope of the logistics park, transforms the input of land, equipment, energy, and other resources as well as income and waste into a unified emergy unit, and carries out a quantitative analysis and comprehensive evaluation of the sustainable development and eco-efficiency of the logistics park. It provides a new perspective for eco-efficiency evaluation of logistics parks. In practice, the use of emergy theory to evaluate the eco-efficiency of logistics park and analyze the correlation between eco-efficiency and various factors can help park managers identify the factors that affect the eco-efficiency and sustainable development of the park, and provide a direction for optimizing resource allocation, adjusting business structure, and improving eco-efficiency. The eco-efficiency optimization decision also provides a theoretical reference for other logistics parks.

\section{Method}

\subsection{Boundary and scope}

Emergy method was founded by Odum, a famous American ecologist, in the 1980s. This method 
converts the different kinds of materials and energy flowing and stored in the ecological economic system, such as rain, wind, coal, oil, natural gas, capital, technology, labor, etc., into a unified solar energy value, and makes a quantitative analysis of them, which provides a new method to study the contribution of ecosystem to social and economic development.The calculation formula is as follows:

$$
E M=U E V \times N
$$

Where EM is emergy, UEV is the emergy conversion rate of different substances, and $\mathrm{N}$ is the different units of input flow (mass $\mathrm{g}$ or energy $\mathrm{J}$ ).

Logistics park is an area where logistics operations are relatively concentrated. It is a place where logistics facilities and equipment are used to manage and engage in logistics activities with specific functions. It is a logistics assembly point with a certain scale and comprehensive service functions. Generally, it includes comprehensive function, intensive function, information trading function, centralized storage function, distribution processing function, multimodal transport function, auxiliary service function, parking function, etc. Its profit mainly comes from land appreciation, rental income, service fees, project investment income and other income.

During the operation of the logistics park, many types of emergy need to be invested, including mainly renewable energy from the environment, such as solar energy, wind energy, geothermal energy, and energy input outside the park. It also refers to non-renewable energy, such as water, electricity, coal, and other input such as land resources, facilities and equipment costs, capital investment, human resources, and information costs required in the operation process.

The emergy output of logistics park is the business income and net profit brought by logistics and related services, as well as various wastes generated in the operation process. Considering the convenience and feasibility of the model calculation, social factors and investor risk are not considering. According to the activity flow and characteristics of the logistics park, the boundary is determined and the emergy flow diagram of the logistics park is drawn, as shown in Figure 1.

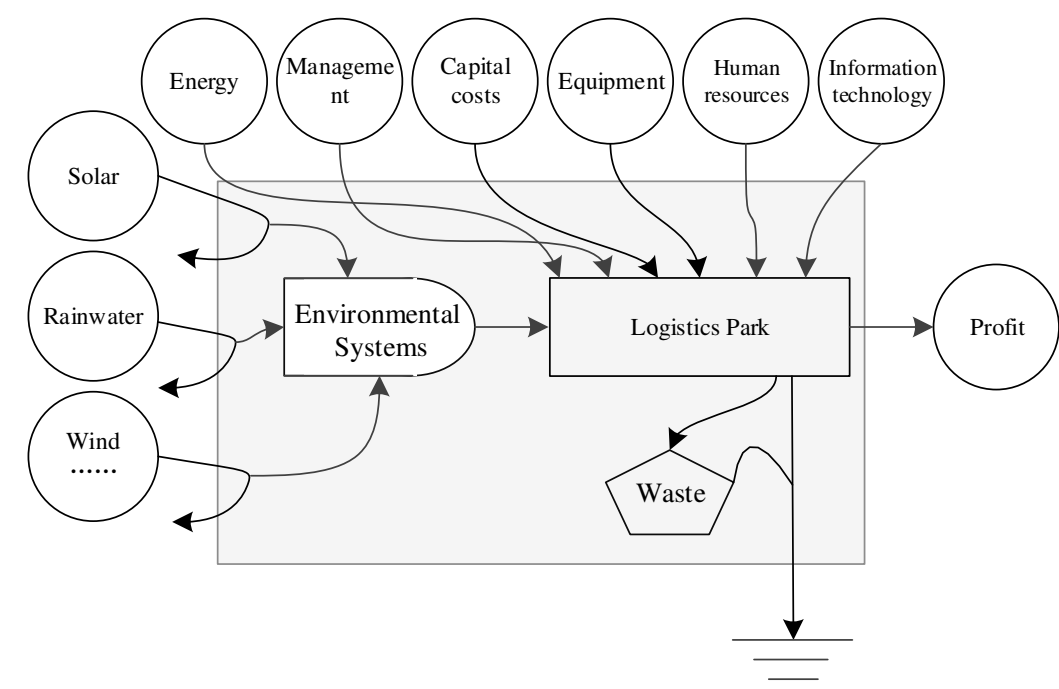

Figure 1. Emergy system diagram of a logistics park. 


\subsection{Data collection and emergy measurement model}

From Figure 1, we can see the various elements of input and output of the logistics park. These elements have the characteristics of many types, large quantities, and different dimensions. Based on the above formula, we convert the material energy of different categories and units into solar energy value and construct the input and output emergy measurement model of logistics parks as follows.

\subsubsection{Input emergy}

(1) Emergy of energy. The energy input of the logistics park includes two aspects: renewable resources from the system itself, including solar energy, rainwater, and wind energy, and so on that provided by nature. It is generally believed that the logistics system is less dependent on the natural environment and uses fewer renewable resources. The other side is various energy sources from outside the system, such as water, electricity, fuel oil, and coal. They ensure the logistics service process like transportation, loading, and unloading, storage, etc.

$$
M_{n}=\sum_{i=1}^{I} n^{i} \times U E V_{n}^{i}
$$

where $M_{n}$ refers to the emergy provided by various energy sources in the logistics system, $n_{i}$ represents the $i$-th type of energy, and $i$ is the total number of energy types used in the logistics system.

(2) Emergy of management. Due to various organization and management activities of the logistics park, corresponding management expenses are generated, which refer mainly to various expenses generated by the management department of the park, including travel expenses of various personnel, material consumption, and expenses incurred due to office needs, safety inspection and maintenance expenses, conference expenses, etc.

$$
M_{g}=\sum_{i=1}^{I} g^{i} \times U E V_{g}^{i}
$$

where $\mathrm{M}_{\mathrm{g}}$ refers to the emergy generated by various management costs in the logistics system, $\mathrm{g}_{\mathrm{i}}$ represents the $\mathrm{i}$-th management cost generated in the logistics system, and i is the total number of management expense types used in the logistics system.

(3) Emergy of capital costs. To meet the needs of a large number of land and logistics facilities and equipment, the logistics park needs to use more funds, resulting in fund-raising costs and capital occupation costs, including printing fees, notarization fees, guarantee fees, etc., which are generated by issuing stocks and bonds, shareholders' dividends paid for occupying other people's funds, interest expenses incurred by debt financing, and the opportunity cost of occupying internal funds.

$$
M_{z}=\sum_{i=1}^{I} z^{i} \times U E V_{z}^{i}
$$

where $\mathrm{M}_{\mathrm{Z}}$ refers to the emergy generated by various capital costs in the logistics system, $\mathrm{z}_{\mathrm{i}}$ represents the $i$-th capital cost generated in the logistics system, and $i$ is the total number of capital cost types used in the logistics system

(4) Emergy of equipment. Logistics Park production and operation process cannot be separated from a variety of logistics infrastructure, such as shelves, forklifts, conveyor belts, cranes, etc. 
Equipment emergy refers to the maintenance cost and depreciation cost of logistics infrastructure equipment.

$$
M_{q}=\sum_{i=1}^{I} q^{i} \times U E V_{q}^{i}
$$

where $\mathrm{M}_{\mathrm{q}}$ refers to the emergy generated by various logistics equipment in the logistics system, $\mathrm{q}_{\mathrm{i}}$ represents the $\mathrm{i}$-th equipment cost generated in the logistics system, and $\mathrm{i}$ is the total number of equipment cost types used in the logistics system.

(5) Emergy of human resources. The human resource cost of a logistics park consists of four parts: acquisition cost refers to the cost incurred in the process of recruitment; development cost includes all kinds of refresher training expenses of employees; use cost refers to the salary, bonus, performance, welfare, allowance and other expenses incurred in the process of using human resources in the park; turnover cost refers to the compensation expense and the replacement expense of the vacant position due to the employee's resignation.

$$
M_{r}=\sum_{i=1}^{I} r^{i} \times U E V_{r}^{i}
$$

where Mr refers to the emergy generated by human resource activities in the logistics system, $r_{i}$ represents the $\mathrm{i}$-th human resource cost generated in the logistics system, and $\mathrm{i}$ is the total number of human resource cost types used in the logistics system.

(6) Emergy of information. As an indispensable part of the logistics park, the logistics information platform plays an important role in the park. It is the link and support of logistics park operation, which improves logistics efficiency and logistics service. The emergy of information includes the cost of hardware construction and software development in the construction of an information platform, and the cost of use, management, and maintenance in the operation of the platform.

$$
M_{p}=\sum_{i=1}^{I} p^{i} \times U E V_{p}^{i}
$$

where $M_{p}$ refers to the emergy generated by information activities in the logistics system, $\mathrm{p}_{\mathrm{i}}$ represents the $\mathrm{i}$-th information cost generated in the logistics system, and $\mathrm{i}$ is the total number of information cost types used in the logistics system.

\subsubsection{Output emergy}

(1) Emergy of waste. In the process of warehousing, handling, transportation, and other services provided by the logistics park, waste gas, wastewater, and solid waste will be discharged, as well as the loss caused by improper land use, forming the waste energy value of the park.

$$
M_{f}=\sum_{i=1}^{I} f^{i} \times U E V_{f}^{i}
$$

where $\mathrm{M}_{\mathrm{f}}$ refers to the emergy of various wastes generated in the logistics system, fi represents the $\mathrm{i}$-th waste generated by the logistics system, and $\mathrm{i}$ is the total number of waste types generated by the 
logistics system.

(2) Emergy of net profit. The logistics park provides other enterprises with warehousing, transportation, information processing, and other logistics services and various value-added services, obtains various incomes such as plant rent, equipment rent, information fee, and service fee. After removing various costs, the net profit of the park is obtained.

$$
M_{j}=\sum_{i=1}^{I} j^{i} \times U E V_{j}^{i}
$$

where $\mathrm{M}_{\mathrm{j}}$ is the emergy of the net profit generated in the logistics system, $\mathrm{j}_{\mathrm{i}}$ is the $\mathrm{i}$-th net profit generated by the logistics system, and i is the total net profit type of the logistics system.

\subsection{Eco-efficiency evaluation model}

There are different types of logistics parks, and their roles in the development of modern logistics also differ. However, no matter what kind of logistics park, to achieve long-term and sustainable development, it is necessary to make their contribution value to the external system, that is, the output value is greater than the input value for a long time. Therefore, evaluating the eco-efficiency of the logistics park is necessary.

Eco-efficiency refers to the efficiency of ecological resources to meet human needs, which is the ratio of output to input, reflecting the relationship between economic output and environmental impact, that is, the ratio of economic value increment to environmental impact increment. Improving ecological economic efficiency means using fewer resources and less environmental damage to achieve higher economic benefits through ecological improvement. The eco-efficiency of the logistics industry reflects the ratio of input (consumption of resources and energy) to output (value and waste of logistics services provided) and is an effective tool to measure the economic and environmental benefits of the logistics industry.

Considering the comprehensive effects of the park on the environment and economy, the eco-efficiency evaluation index of sustainable development of logistics parks can be constructed as follows.

$$
E_{c}=\frac{\int_{t_{0}}^{t_{1}} M_{j}-M_{f}}{\int_{t_{0}}^{t_{1}} M_{n}+M_{g}+M_{z}+M_{q}+M_{r}+M_{p}}
$$

The above formula is the direct quantitative relationship between the external contribution value of the logistics park system and the resources to be invested. It describes the eco-efficiency of the logistics park; the higher the eco-efficiency, the better.

\subsection{Correlation analysis}

To improve the eco-efficiency of the logistics park, it is necessary to study the relationship between the input and output factors of the park logistics system and the eco-efficiency of the park and put forward suggestions for improvement. The correlation coefficient can reflect the closeness of the 
relationship between variables, the calculation formula is as follows.

$$
R_{x y}=\frac{S_{x y}}{S_{x} S_{y}}
$$

where $R_{x y}$ is the sample correlation coefficient, $S_{x y}$ is the sample covariance, $S_{x}$ is the sample standard deviation of $\mathrm{x}$, and $\mathrm{S}_{\mathrm{y}}$ is the sample standard deviation of $y$.

$R_{x y}$ values range from -1 to 1.0 means the two variables are not related. The closer the data are to 0 , the weaker the correlation.

When $R_{x y}<0$, it indicates that this factor is negatively correlated with the eco-efficiency of the logistics park and - 1 means the two variables have a completely negative correlation.

When $R_{x y}>0$, it indicates that the factor is positively correlated with the eco-efficiency of the logistics park, and 1 means that the two variables have a completely linear correlation.

\subsection{Optimization decision}

The decision-making process of optimizing the ecological efficiency of the logistics park is as follows:

(1) Based on the analysis of the input and output emergy of the logistics park, combined with the activity process and park characteristics of the logistics park, the emergy flow graph measurement technology is used to determine the boundary of the logistics park and draw the emergy flow diagram to clarify the current emergy flow of the logistics park.

(2) Correlation analysis was used to analyze the effects of the various factors of the logistics park, including energy, capital investment, equipment, information technology, human resources, and waste emissions on the ecological efficiency of the park and measure the degree of correlation to determine the key factors affecting the ecological efficiency of the park.

(3) The key factors affecting the ecological efficiency of the park were improved, and the improvement effect was evaluated by combining the analysis results and the actual situation of the logistics park.

(4) Summarize the effective methods, standardize them, and bring them into the company management system.

\section{Case study}

\subsection{Background}

$\mathrm{H}$ logistics park covers an area of 35 hectares, with a registered capital of 1,300,000,000 CNY (unit of Chinese currency), and more than 200 people of various types. Based on the industrial park, the logistics park serves the surrounding economic areas and provides an integrated logistics operation platform for the modern manufacturing industry, third-party logistics enterprises, and business circulation industry. It is a multi-functional, regional demonstration, service-oriented modern logistics park that integrates basic logistics services, such as public rail water multi-modal transportation, warehousing and distribution, transfer distribution, container transportation, and other extended 
343 logistics services, such as raw material procurement, warehouse receipt pledge, supply chain 344 management, information service, etc. Since the establishment of the logistics park, the customer group

345 has been stable, and the annual operating income and net profit are considerable. However, in the case 346 of additional investment in equipment and information technology, the profit of the logistics park did 347 not achieve the expected growth. Given this, the project team investigated the park and proposed the 348 eco-efficiency optimization decision-making oriented to the sustainable development of the logistics 349 park.

\section{$350 \quad 4.2$ Results}

351 Relevant data from 2014 to 2018 were collected with the help of relevant personnel of the park 352 and by consulting the company's public annual report and combined with the investigation of the 353 logistics park. In the process of data collection, the data about management cost, capital cost, 354 equipment management, information, human resources, incomes and net profit, not material flow but 355 monetary data provided by enterprises. In order to ensure the accuracy of the original data and the 356 simplicity of calculation, for this part of the data, we use monetary data for research. The appropriate 357 emergy conversion rate was selected by consulting the literature. The specific data and emergy flow are 358 shown in Tables 1 and 2.

Table 1. Energy Data of the Logistics Park in 2014-2018.

\begin{tabular}{|c|c|c|c|c|c|c|c|}
\hline \multirow{2}{*}{ Collection Object } & \multicolumn{5}{|c|}{ Original Data } & \multirow{2}{*}{$\begin{array}{c}\text { Emergy Conversion } \\
\text { Rate (Sej/Unit) }\end{array}$} & \multirow{2}{*}{ Reference } \\
\hline & 2014 & 2015 & 2016 & 2017 & 2018 & & \\
\hline \multicolumn{8}{|c|}{ Renewable resources in the system } \\
\hline Solar Energy (J) & $7.05 \mathrm{E}+15$ & $7.11 \mathrm{E}+15$ & $6.99 \mathrm{E}+15$ & $7.26 \mathrm{E}+15$ & $7.17 \mathrm{E}+15$ & $1.00 \mathrm{E}+00$ & Odum,1996 \\
\hline Wind Energy (J) & $2.45 \mathrm{E}+11$ & $3.00 \mathrm{E}+11$ & $2.65 \mathrm{E}+11$ & $2.70 \mathrm{E}+11$ & $3.05 \mathrm{E}+11$ & $6.63 \mathrm{E}+02$ & Odum,1996 \\
\hline $\begin{array}{l}\text { Rainwater Potential } \\
\text { Energy }(\mathrm{J})\end{array}$ & $3.40 \mathrm{E}+08$ & $3.80 \mathrm{E}+08$ & $2.95 \mathrm{E}+08$ & $4.55 \mathrm{E}+08$ & $4.20 \mathrm{E}+08$ & $8.89 \mathrm{E}+03$ & Odum,1996 \\
\hline $\begin{array}{l}\text { Rainwater Chemical } \\
\text { Energy }(\mathrm{J})\end{array}$ & $8.90 \mathrm{E}+07$ & $9.35 \mathrm{E}+07$ & $8.15 \mathrm{E}+07$ & $9.85 \mathrm{E}+07$ & $9.55 \mathrm{E}+07$ & $1.55 \mathrm{E}+04$ & Odum,1996 \\
\hline Geothermal Energy (J) & $4.60 \mathrm{E}+12$ & $5.15 \mathrm{E}+12$ & $5.65 \mathrm{E}+12$ & $4.90 \mathrm{E}+12$ & $5.25 \mathrm{E}+12$ & $2.90 \mathrm{E}+04$ & Odum,1996 \\
\hline \multicolumn{8}{|c|}{ Input Resources } \\
\hline Water $(\mathrm{G})$ & $2.25 \mathrm{E}+09$ & $2.90 \mathrm{E}+09$ & $3.30 \mathrm{E}+09$ & $3.75 \mathrm{E}+09$ & $3.35 \mathrm{E}+09$ & $4.10 \mathrm{E}+04$ & Odum,1996 \\
\hline Electric $(J)$ & $1.45 \mathrm{E}+12$ & $1.50 \mathrm{E}+12$ & $1.80 \mathrm{E}+12$ & $1.98 \mathrm{E}+12$ & $2.15 \mathrm{E}+12$ & $1.60 \mathrm{E}+05$ & Odum,1996 \\
\hline Fuel (J) & $1.05 \mathrm{E}+12$ & $1.15 \mathrm{E}+12$ & $1.40 \mathrm{E}+12$ & $1.47 \mathrm{E}+12$ & $1.60 \mathrm{E}+13$ & $6.60 \mathrm{E}+04$ & Odum,1996 \\
\hline $\begin{array}{l}\text { Management Cost } \\
(\mathrm{CNY})\end{array}$ & $3.58 \mathrm{E}+06$ & $4.47 \mathrm{E}+06$ & $5.01 \mathrm{E}+06$ & $5.72 \mathrm{E}+06$ & $6.25 \mathrm{E}+06$ & $8.61 \mathrm{E}+11$ & Cai et al.2018 \\
\hline Capital Cost (CNY) & $5.85 \mathrm{E}+06$ & $6.84 \mathrm{E}+06$ & $6.84 \mathrm{E}+06$ & $7.38 \mathrm{E}+06$ & $7.38 \mathrm{E}+06$ & $8.61 \mathrm{E}+11$ & Cai et al.2018 \\
\hline $\begin{array}{l}\text { Equipment } \\
\text { Management (CNY) }\end{array}$ & $4.12 \mathrm{E}+06$ & $4.89 \mathrm{E}+06$ & $5.05 \mathrm{E}+06$ & $5.95 \mathrm{E}+06$ & $6.27 \mathrm{E}+06$ & $8.61 \mathrm{E}+11$ & Cai et al.2018 \\
\hline Information (CNY) & $7.50 \mathrm{E}+05$ & $8.80 \mathrm{E}+05$ & $8.00 \mathrm{E}+05$ & $1.20 \mathrm{E}+06$ & $5.50 \mathrm{E}+05$ & $8.61 \mathrm{E}+11$ & Cai et al.2018 \\
\hline $\begin{array}{l}\text { Human Resource } \\
\text { (CNY) }\end{array}$ & $4.60 \mathrm{E}+06$ & $4.80 \mathrm{E}+06$ & $5.40 \mathrm{E}+06$ & $6.80 \mathrm{E}+06$ & $7.50 \mathrm{E}+06$ & $8.61 \mathrm{E}+11$ & Cai et al.2018 \\
\hline \multicolumn{8}{|c|}{ Output Resources } \\
\hline
\end{tabular}




\begin{tabular}{lcccccccc}
\hline Incomes (CNY) & $3.42 \mathrm{E}+09$ & $3.68 \mathrm{E}+09$ & $5.34 \mathrm{E}+09$ & $4.82 \mathrm{E}+09$ & $4.10 \mathrm{E}+09$ & $8.61 \mathrm{E}+11$ & Cai et al.2018 \\
Net Profit (CNY) & $6.90 \mathrm{E}+06$ & $6.15 \mathrm{E}+06$ & $6.02 \mathrm{E}+06$ & $7.78 \mathrm{E}+06$ & $1.26 \mathrm{E}+07$ & $8.61 \mathrm{E}+11$ & Cai et al.2018 \\
Wastewater (G) & $1.80 \mathrm{E}+08$ & $2.30 \mathrm{E}+08$ & $2.65 \mathrm{E}+08$ & $3.00 \mathrm{E}+08$ & $2.70 \mathrm{E}+08$ & $1.24 \mathrm{E}+09$ & Liu et al.2021 \\
Waste Gas (G) & $1.70 \mathrm{E}+05$ & $1.80 \mathrm{E}+05$ & $2.35 \mathrm{E}+05$ & $2.30 \mathrm{E}+05$ & $6.30 \mathrm{E}+05$ & $1.84 \mathrm{E}+08$ & Liu et al.2021 \\
Solid Waste (G) & $4.88 \mathrm{E}+06$ & $5.12 \mathrm{E}+06$ & $5.57 \mathrm{E}+06$ & $6.00 \mathrm{E}+06$ & $5.70 \mathrm{E}+06$ & $2.52 \mathrm{E}+08$ & Liu et al.2021 \\
\hline
\end{tabular}

Table 2. Emergy Data of the Logistics Park in 2014-2018.

\begin{tabular}{|c|c|c|c|c|c|}
\hline \multirow{2}{*}{ Collection Object } & \multicolumn{5}{|c|}{ Emergy Data } \\
\hline & 2014 & 2015 & 2016 & 2017 & 2018 \\
\hline \multicolumn{6}{|c|}{ Renewable resources in the system } \\
\hline Solar energy & $7.05 \mathrm{E}+15$ & $7.10 \mathrm{E}+15$ & $7.00 \mathrm{E}+15$ & $7.25 \mathrm{E}+15$ & 7.17E+15 \\
\hline Wind energy & $1.62 \mathrm{E}+14$ & $1.99 \mathrm{E}+14$ & $1.76 \mathrm{E}+14$ & $1.79 \mathrm{E}+14$ & $2.02 \mathrm{E}+14$ \\
\hline Rainwater potential energy & $3.02 \mathrm{E}+12$ & $3.38 \mathrm{E}+12$ & $2.62 \mathrm{E}+12$ & $4.04 \mathrm{E}+12$ & $3.73 \mathrm{E}+12$ \\
\hline Rainwater chemical energy & $1.37 \mathrm{E}+12$ & $1.44 \mathrm{E}+12$ & $1.26 \mathrm{E}+12$ & $1.52 \mathrm{E}+12$ & $1.47 \mathrm{E}+12$ \\
\hline Geothermal energy & $1.33 \mathrm{E}+17$ & $1.49 \mathrm{E}+17$ & $1.64 \mathrm{E}+17$ & $1.42 \mathrm{E}+17$ & $1.52 \mathrm{E}+17$ \\
\hline \multicolumn{6}{|c|}{ Input resources } \\
\hline Water & $9.23 \mathrm{E}+13$ & $1.19 \mathrm{E}+14$ & $1.35 \mathrm{E}+14$ & $1.54 \mathrm{E}+14$ & $1.37 \mathrm{E}+14$ \\
\hline Electric & $2.32 \mathrm{E}+17$ & $2.40 \mathrm{E}+17$ & $2.88 \mathrm{E}+17$ & $3.17 \mathrm{E}+17$ & $3.44 \mathrm{E}+17$ \\
\hline Fuel & $6.93 \mathrm{E}+16$ & $7.59 \mathrm{E}+16$ & $9.24 \mathrm{E}+16$ & $9.70 \mathrm{E}+16$ & $1.06 \mathrm{E}+18$ \\
\hline Management cost & $3.08 \mathrm{E}+18$ & $3.85 \mathrm{E}+18$ & $4.31 \mathrm{E}+18$ & $4.93 \mathrm{E}+18$ & $5.38 \mathrm{E}+18$ \\
\hline Capital cost & $5.04 \mathrm{E}+18$ & $5.89 \mathrm{E}+18$ & $5.89 \mathrm{E}+18$ & $6.35 \mathrm{E}+18$ & $6.35 \mathrm{E}+18$ \\
\hline Equipment Management & $3.55 \mathrm{E}+18$ & $4.21 \mathrm{E}+18$ & $4.35 \mathrm{E}+18$ & $5.12 \mathrm{E}+18$ & $5.40 \mathrm{E}+18$ \\
\hline Information & $6.46 \mathrm{E}+17$ & $7.58 \mathrm{E}+17$ & $6.89 \mathrm{E}+17$ & $1.03 \mathrm{E}+18$ & $4.74 \mathrm{E}+17$ \\
\hline Human resource & $3.96 \mathrm{E}+18$ & $4.13 \mathrm{E}+18$ & $4.65 \mathrm{E}+18$ & $5.85 \mathrm{E}+18$ & $6.46 \mathrm{E}+18$ \\
\hline \multicolumn{6}{|c|}{ Output resources } \\
\hline Incomes & $2.94 \mathrm{E}+21$ & $3.17 \mathrm{E}+21$ & $4.60 \mathrm{E}+21$ & $4.15 \mathrm{E}+21$ & $3.53 \mathrm{E}+21$ \\
\hline Net profit & $5.94 \mathrm{E}+18$ & $5.30 \mathrm{E}+18$ & $5.18 \mathrm{E}+18$ & $6.70 \mathrm{E}+18$ & $1.08 \mathrm{E}+19$ \\
\hline Wastewater & $2.23 \mathrm{E}+17$ & $2.85 \mathrm{E}+17$ & $3.29 \mathrm{E}+17$ & $3.72 \mathrm{E}+17$ & $3.35 \mathrm{E}+17$ \\
\hline Waste gas & $3.13 \mathrm{E}+13$ & $3.31 \mathrm{E}+13$ & $4.32 \mathrm{E}+13$ & $4.23 \mathrm{E}+13$ & $1.16 \mathrm{E}+14$ \\
\hline Solid waste & $1.23 \mathrm{E}+15$ & $1.29 \mathrm{E}+15$ & $1.40 \mathrm{E}+15$ & $1.51 \mathrm{E}+15$ & $1.44 \mathrm{E}+15$ \\
\hline
\end{tabular}

According to Table 2 and the above formula, the eco-efficiency of the logistics park for five consecutive years as shown in Table 3 can be calculated.

Table 3. Sustainable development index and eco-efficiency of H Logistics Park in 2014-2018

\begin{tabular}{lrrrrr}
\hline Year & 2014 & 2015 & 2016 & 2017 & 2018 \\
\hline Eco-efficiency & $3.42 \mathrm{E}-01$ & $2.59 \mathrm{E}-01$ & $2.37 \mathrm{E}-01$ & $2.65 \mathrm{E}-01$ & $4.10 \mathrm{E}-01$ \\
\hline
\end{tabular}

Ecological efficiency can reflect the level of economy and environment of logistics park in a certain period, detect its change trend, and measure the coordination degree between economy and 
environment comprehensively. By analyzing the correlation between eco-efficiency and various input resources, we can determine the order of improvement of resource utilization efficiency. We believe that the decline of the eco-efficiency index indicates that resource consumption is too large, and the utilization rate is low in the logistics park, and efforts should be made to improve the resource utilization efficiency. The eco-efficiency index is relatively stable, indicating that the effects of the park on the environment can be maintained at a certain level, and the eco-efficiency can be improved through technological innovation and industrial structure optimization. The eco-efficiency index is increasing, indicating that the economic or environmental benefits of the park are constantly improving and that the adverse effects on the environment are gradually reducing, which is an effective performance of sustainable development.

The above data shows that the eco-efficiency of the logistics park decreased from 0.34 to 0.26 in 2015, which was relatively stable and maintained at about 0.25 during 2015-2017, indicating that the logistics park has more resources input, low resource utilization efficiency, and the various resources have not been rationally utilized. It is necessary to improve resource utilization efficiency and optimize the business structure. In 2018, the index rose to 0.41 , the eco-efficiency of the park was slightly improved.

Based on the calculation of eco-efficiency indices, the correlation between eco-efficiency of the logistics system of the logistics park and the influencing factors is calculated, and the results obtained are shown in Fig 2.

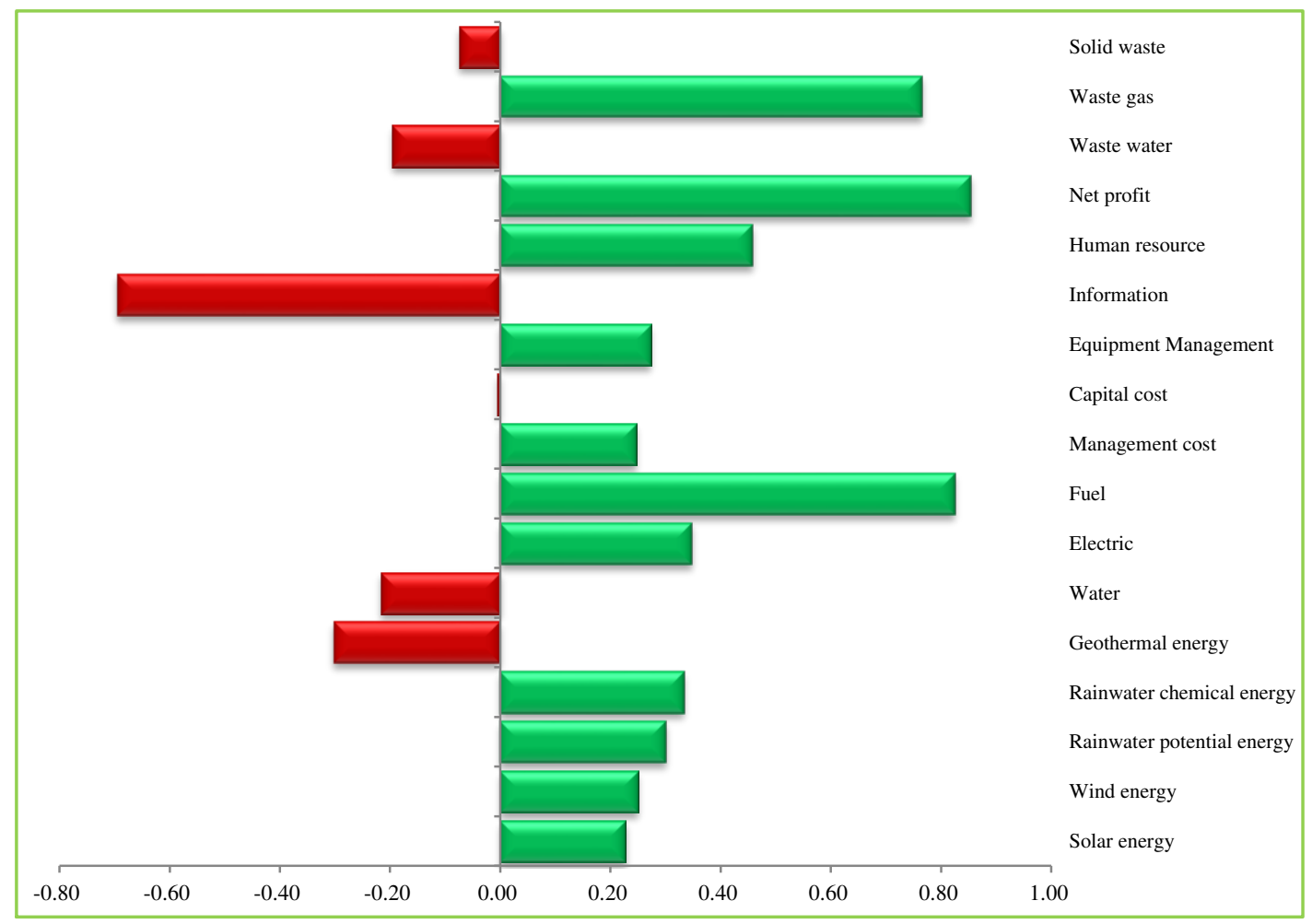

Figure 2. Results of correlation analysis 
The above data shows the relationship between various factors of the logistics park and eco-efficiency. The variables with a strong correlation to eco-efficiency are fuel oil, information technology, net profit, and waste gas. Information technology is negatively correlated with ecological efficiency, and the other three factors are positively correlated.

It is obviously that net profit is positively correlated with ecological efficiency, a strong positive correlation between fuel oil, waste gas, and eco-efficiency was also observed. The main reason for this observation is that in 2017, the logistics park developed a new container business, which brought more profits to enterprises. In the process of business development, the front crane is used to load and unload the container, which uses more fuel and produces a significant amount of waste gas Therefore, it also had a considerable effect on the sustainable development of the logistics park. The park should use lean fuel to reduce fuel consumption and exhaust emissions, and to improve the efficiency of the logistics park.

Logistics information technology has a very important positive effect on logistics enterprises, which can help logistics enterprises improve logistics efficiency and reduce costs. The logistics park is aware of the importance of information technology and has been focusing on its investments. The park's information technology investment accounts for about $10 \%-15 \%$ of the net profits. However, the information investment is too fast, resulting in the inefficient use of information technology (the correlation coefficient is -0.6949). The park should make full use of existing information technology, strengthen the training of staff to improve the level of information technology, use information technology reasonably and efficiently, and excavate it further.

The correlation between capital cost and eco-efficiency is very low, and the correlation coefficient is only -0.0063 , which is almost negligible. This finding shows that in the development process of the logistics park, the effect of capital on eco-efficiency is very small. Although the logistics park increased capital investment in 2015 and 2017 no significant change in eco-efficiency was observed. In the future development process, the logistics park should reduce capital investment, tap the internal potential of the park, and improve the efficiency of capital use.

As an emerging logistics park, the efficiency of human resources is low (correlation coefficient is 0.4577) and personnel structure is unreasonable, making it necessary to streamline the organization, strengthen functional departments, and fully mobilize the enthusiasm of staff. The role of logistics infrastructure equipment is not fully realized (correlation coefficient is 0.2729), logistics management mode needs to be adjusted appropriately (correlation coefficient is 0.2466 ), and transformation and upgrading are needed. The correlation between various renewable resources and ecological efficiency is relatively low, which is $0.2273,0.2492,0.3000,0.3336$. and -0.3017 respectively. It shown that in the production process of logistics park, the participation degree of renewable resources from within the system is very low, which does not give full play to its role in sustainable development. 
Considerable waste is produced in the logistics process of the park. The emergy waste rate of the park is about $1.8 \%$, and the recycling degree is poor. The relevant personnel in the park do not focus to waste management and lack the corresponding management of garbage recycling, which brings certain pressure to the environment. Reducing the discharge of wastewater and solid waste have positive effects on eco-efficiency (the correlation coefficients with wastewater is - 0.1962, and with solid waste is -0.0747$)$.

\subsection{Optimization suggestions}

\subsubsection{Optimize the resource allocation of the park}

The correlation coefficient between capital cost and eco-efficiency of the park is only -0.0063 , indicating a mismatch between input and output in Logistics Park, and that the resource input is redundant. Therefore, the park should strengthen the management and control of resource input and focus on improving resource utilization rate (Han et al.2021; Wang et al.2021). The logistics park can consider internal restructuring, optimize and adjust existing assets, transfer the focus of resource input, and employ the transferred human, financial and material resources into improving the quality of employees, strengthening technological innovation, optimizing management mechanism, and so on, to improve the input quality of various elements, improve the efficiency of asset utilization and financial leverage effect, bring more output for enterprises, and consequently improve the eco-efficiency of the logistics park.

\subsubsection{Improve the application ability of information technology}

The application of logistics information technology in logistics parks can expand the development space of logistics service in the park, improve service quality, reduce operation costs, and improve operational efficiency. First, the park should enhance the application ability of the existing information technology and strengthen the application of logistics information technology in production and organization. The above data shows that the park attaches great importance to information technology and has high investment, but the efficiency of information technology is insufficient (correlation coefficient is -0.6949). The park should promote the integration and processing of logistics information, excavate useful information, and provide a relevant basis for management decision-making. In the process of loading, unloading, transportation, warehouse management, purchasing, ordering, order processing, distribution, and shipping, full use of information technology should be made to improve the level of automation, promote the process of automation, and use the powerful information network system to realize convenient communication with upstream and downstream enterprises and improve the controllability of logistics service quality and the service efficiency of logistics. Second, the logistics park needs to maintain the importance of logistics technology innovation by strengthening the cooperation between the park and other innovation platforms, such as relevant universities and 
scientific research institutions, promote scientific and technological innovation in the park, and form the integration of park development and scientific and technological innovation.

\subsubsection{Optimize business structure and expand logistics business scope}

The operating income of the logistics park is high, but its net profits is very low. The current development situation indicates that the logistics park will continue to focus on the traditional logistics field in the main business, provide transportation services and warehousing services for customers, and provide freight forwarding services, etc.; however, the lack of diversified business development greatly increases the management risk of the park. Therefore, the logistics park should optimize the existing logistics business and the structure of logistics products, strengthen superior products and services continuously, and eliminate the logistics products and services with poor market prospects, to improve the core competitiveness of the market. It should also further expand its business scope as well as its value-added services in circulation processing, logistics cost control, and logistics scheme design, and effectively increase the operating profits of the park. Expanding the logistics business can yield great operating benefits, thereby effectively improving the efficiency of logistics enterprises.

\subsubsection{Reduce waste discharge and improve sustainable development and eco-efficiency}

The waste emissions of logistics parks have less waste emissions as compared to various industrial parks and thus, many parks do not pay much attention to waste emissions. Logistics parks have considerable amount of waste in the process of loading and unloading, warehousing, circulation processing, and supporting catering accommodation. From the emergy point of view, Table 2 shows that the emergy of waste in the logistics park accounts for about $5 \%$ of the output, which reduces the sustainable development index of the park and also has a certain effect on the eco-efficiency of the park. Reducing the discharge of waste has a positive effect on both. Therefore, on the one hand, the park should reduce its waste discharge in the process of operation, form a waste recycling system such as a sustainable drainage system (Ibáñez et al. 2019), and strengthen the supervision and management of waste. On the other hand, the use of clean energy should be increased while the environmental pollution caused by harmful gas emissions should be reduced. For example, in terms of logistics facilities and equipment, new energy equipment should be selected as far as possible under the premise of meeting the same functions. When cooperating with transportation companies and other logistics companies, they should be encouraged to use new energy vehicles and equipment.

\subsection{Management implications}

Compared with the familiar literatures on Logistics ecological efficiency (Kunyazov et al.2020; Zheng et al.2020; Zhang et al.2020), this paper has the following advantages. First, emergy method is used to evaluate the input and output of logistics park, it fully considering various natural factors, unifying the measurement of environment, resources, labor, information, etc. to evaluate the development status of eco economic system, which provides an important measurement standard for 
the quantitative research of ecosystem, and also provides $r$ an objective standard and scientific basis for the evaluation of sustainable development ability of logistics system. Secondly, it analyzes the direct positive or negative relationship between the influencing factors and the ecological efficiency of the logistics park from the perspective of correlation, and analyzes the reasons. On this basis, it puts forward the optimization decision-making method of the logistics park. It can help the decision-makers of logistics park to make correct decisions, so as to improve energy efficiency, avoid ineffective or inefficient investment, reduce waste emissions, and improve the ecological efficiency of logistics park.

The logistics park maintains a dynamic balance between the park and the environment through the circulation of input and output, inputs the energy and various resources needed for its survival and development, exports products, services, or wastes, and outputs that react to the environment. A long-term process or state of production system must be in the recognized value system, and its ecological efficiency must be greater than 1 , that is, the output must be greater than the input, and the larger the better. Considering that low-profit trade accounts for a large proportion of the services provided by logistics parks when incomes are used to measure eco-efficiency, the eco-efficiency is higher, and the output is measured by net profit and waste.

Combined with the above research and conclusion, we obtain the following management enlightenment:

First, an evaluation of the eco-efficiency of the logistics park can help the logistics park correctly understand its effects on the environment, promote the park to strengthen the effective use of resources, and reduce the negative effects on the environment. It is a beneficial attempt to improve the eco-efficiency of the logistics park by using emergy theory.

Second, the logistics park is a complex ecosystem with multi-input and multi-output, and its input resources include renewable energy, management costs, human resources, information technology, etc. The input and output of resources will affect the eco-efficiency of the park to a certain extent. Hence, the identification and analysis of various influencing factors are conducive to the effective improvement of eco-efficiency and the sustainable development ability of logistics parks.

Third, improving the ability for sustainable development and eco-efficiency of logistics parks is the embodiment of the social responsibility of the logistics park. Identifying the relevant influencing factors and strengthening it will help the logistics park to reduce costs, improve efficiency, establish a good image, and avoid administrative penalties from the government.

\section{Conclusion}

This paper studies the eco-efficiency of the logistics park based on the emergy and eco-efficiency theories, constructs an evaluation model of eco-efficiency of a logistics park, and analyzes H Logistics Park as an example. Through the analysis of the correlation between various factors and eco-efficiency, the paper puts forward suggestions for optimizing the eco-efficiency of logistics parks, including 
optimizing park resource allocations, improving the application ability of information technology, expanding logistics business and logistics business scope, and reducing waste discharge, etc. It can provide decision-making suggestions for park managers.

The main innovation points are as follows. This paper proposes a method to measure, evaluate, and optimize the eco-efficiency of a logistics system based on emergy. From the perspective of emergy, the input-output data of the logistics system are processed in a unified dimension, and the eco-efficiency of the logistics system quantified. From the perspective of relevance, this paper reveals the relationship between various influencing factors and the eco-efficiency of the logistics system, which provides a decision-making basis for improving the eco-efficiency of the logistics system.

The evaluation model and optimization method of eco-efficiency based on emergy can be applied to the comprehensive evaluation of sustainable development and eco-efficiency of operable logistics parks and help them enhance their core competitiveness further. This evaluation system is highly operational in practical application, it can supervise the rational use of various resources and the effective control of environmental pollution in the logistics park, and provide decision support for the park managers to formulate sustainable development strategies and improve ecological efficiency.

Considering the availability of data and the simplicity of calculation, part of the original data we collected about the logistics park is monetary data, while the form of energy flow and material flow will better reflect the essence of emergy method. The maintenance and operation of the ecosystem and the development of the human social and economic system all depend on the maintenance of solar energy, and the source of all kinds of energy and matter should ultimately come down to solar energy. Besides, social problems, threats and risks faced by investors are difficult to quantify and are not involved in the paper. How to show all the original data of logistics park in the form of energy or matter, and consider the social problems, threats and risks faced by investors is the direction of our next efforts to explore. In addition, the relationship between sustainable development and ecological efficiency of logistics park, the role of supply chain management and reverse logistics in logistics park will be further studied in the future.

Author Contributions: Conceptualization, C.W.; methodology, C.W. and C.Z.; investigation, F.H.; resources, Y.W.; data curation, C.W. and L.Y.; writing-original draft preparation, C.W. and C.Z.; writing-review and editing, C.W and C.L.; All authors read and approved the final manuscript.

Funding: This research is supported by Humanities and Social Sciences Research Projects of Anhui Universities (No.SK2019A0538), Key scientific research projects of Suzhou University (No.2019yzd13), Primary Research and Development Program of Anhui Province (201904a05020087), Natural Science Foundation of Anhui Province (2008085me150), Key project of natural science research in Universities of Anhui Province (kj2019a0673) and National Social Science Project (20bg1108), Excellent Academic and Technical Backbone of Suzhou University (No.2018XJGG12).

Conflicts of Interest: The authors declare that they have no competing interests. 
Ethical Approval: Not applicable

\section{Consent to Participate: Not applicable}

Consent to Publish: Not applicable

Availability of data and materials: All data generated or analysed during this study are included in this published article [and its supplementary information files]

\section{References}

Alfredo G, David L,Abraham C, David L, Hugo O, Leonor P(2018) A methodological framework of eco-efficiency based on fuzzy logic and Life Cycle Assessment applied to a Mexican SME. Environmental Impact Assessment Review 68:38-48.

Bandeira R.A.M, D’Agosto M.A, Ribeiro S. K, Bandeira, A.P.F,Goes, G.V. (2018) A Fuzzy multi-criteria model for evaluating sustainable urban freight transportation operations. Journal of Cleaner Production 184:727-739.

Biagio F. Giannetti, Silvia H.Bonilla, Cecilia M.V.B.Almeida (2013) An emergy-based evaluation of a reverse logistics network for steel recycling. Journal of cleaner production 46:48-57.

Cai W, Liu C, Jia S, Felix T, Chan S, Ma X (2020) An emergy-based sustainability evaluation method for outsourcing machining resources. Journal of Cleaner Production 245:118849.

Cai W, Liu C, Zhang C, Ma M, Rao W, Li W, He K, Gao M (2018) Developing the ecological compensation criterion of industrial solid waste based on emergy for sustainable development. Energy 157: 940-948.

Cuadra M, Rydberg T (2006) Emergy evaluation on the production, processing, and export of coffee in Nicaragua. Ecological Modelling 196, 421-433.

Fan YP, Fang CL (2020) Assessing environmental performance of eco-industrial development in industrial parks. Waste management 107:219-226.

Geng ZQ, Song GL, Han YM, Chu C (2021) Static and dynamic energy structure analysis in the world for resource optimization using total factor productivity method based on slacks-based measure integrating data envelopment analysis. Energy Conversion and Management $228: 113713$.

Han YM, Liu S, Geng ZQ, Gu HC, Qu YX (2021) Energy analysis and resources optimization of complex chemical processes: Evidence based on novel DEA cross-model. Energy 218:119508.

Ibáñez R, Millán P, Valls G, Urios G (2019) Rainwater management with SUDS in logistics platforms: Case of the logistics platform at plot M-1 of the Valencia Logistics Park, Ribarroja del Turia (Valencia). Revista de Obras Publicas 166(3607): 68-73.

Ifeyinwa J O, Simonov K, Himanshu G, Modestus O (2019) Evaluating challenges to implementing eco-innovation for freight logistics sustainability in Nigeria. Transportation Research Part A: Policy and Practice 129:288-305.

Kamran R, Kevin C (2019) Evaluating the sustainability of national logistics performance using Data Envelopment Analysis. Transport Policy 74:35-46.

Kelle P, Song J, Jin M, Schneider H, Claypool C (2019) Evaluation of operational and environmental sustainability tradeoffs in multimodal freight transportation planning. International Journal of Production Economics 209: 411-420.

Kunyazov Y, Shakhman Y, Rakhimova S, Mussina A, Ernazarov T (2020) Design and evaluation of efficiency of macro-logistic systems for countries with developing economy. Entrepreneurship and sustainability issues 8(2):1062-10822021.

Leonardo V, Ricardo R, Lidia A, Marcela C, González-Araya, Alfredo I (2020) The joint use of life cycle assessment and data envelopment analysis methodologies for eco-efficiency assessment: A critical review, taxonomy and future research. Science of The Total Environment 738:139538.

Li G, Sun W, Yuan Q, Liu S (2020) Planning versus the market: Logistics establishments and logistics parks in Chongqing, China. Journal of Transport Geography 82:102599. 
Liu C, Cai W, Dinolov, O (2018) Emergy based sustainability evaluation of remanufacturing machining systems. Energy 150, 670-680.

Liu C, Cai W, Jia S, Zhang M, Guo Y, Hu L, Jiang Z (2018) Emergy-based evaluation and improvement for sustainable manufacturing systems considering resource efficiency and environment performance. Energy conversion and management 177: 176-189.

Liu C, Gao M, Zhu G, Zhang C, Zhang P, Chen J \& Cai W (2021) Data driven eco-efficiency evaluation and optimization in industrial production. Energy 224: 120170.

Liu C, Zhu Q, Wei F, Rao W, Liu J, Hu J, Cai W (2019) An integrated optimization control method for remanufacturing assembly system. Journal of Cleaner Production 248:119261.

Liu W, Wang S, Dong D, Wang J (2020) Evaluation of the intelligent logistics eco-index: Evidence from China. Journal of Cleaner Production 274:123127.

Long R, Ouyang H, Guo H (2020) Super-slack-based measuring data envelopment analysis on the spatial-temporal patterns of logistics ecological efficiency using global Malmquist Index model. Environmental Technology \& Innovation 18:100770.

Makarov E, Nikolaeva Y, Shubina E, Taidaev R (2019) Sustainable Functioning of a Logistic Industrial Park as a Factor of Economic Security of the Region. Advances in Intelligent Systems and Computing726:511-517.

May G, Stahl B, Taisch M (2016) Energy management in manufacturing: Toward eco-factories of the future-A focus group study. Applied Energy 164: 628-638.

Melkonyan A, Gruchmann T, Lohmar F, Kamath V, Spinler S (2020) Sustainability assessment of last-mile logistics and distribution strategies: The case of local food networks. International Journal of Production Economics 228:107746.

Nuri C, Murat K, Shiva A (2019) Eco-efficiency of electric vehicles in the United States: A life cycle assessment based principal component analysis. Journal of Cleaner Production 212:515-526.

Odum T (1996) Environmental Accounting: Emergy and Environ-Mental Decision making; Wilely: Hoboken, NJ, USA.

Pan H, Geng Y, Tian X, Wilson J, Chen W, Zhong S, Song X (2019) Emergy-based environmental accounting of one mining system. Environmental Science and Pollution Research 26:1459814615.

Pereira C P, Prata D M, Santos L S, Monteiro L (2018) Development of eco-efficiency comparison index through eco-indicators for industrial applications. Brazilian Journal of Chemical Engineering 35(1): 69-90.

Quariguasi Frota Neto J, Walther G, Bloemhof J, van Nunen J. A. E. E., Spengler T (2009) A methodology for assessing eco-efficiency in logistics networks. European Journal of Operational Research 193(3):670-682.

Schaltegger S, Burritt R (2000) Contemporary environmental accounting: Issues, concepts, and practice. Sheffield: Greenleaf Pubns.

Schmidheiny S (1992) Changing course: A global business perspective on development and the environment. Cambridge: The MIT Press.

Shamsheer H, Ismer B, Pomi S, Yidirim C (2020) Evaluating eco-efficiency and optimal levels of fertilizer use based on the social cost and social benefits in tea production. Environmental Science and Pollution Research 27:33008-33019.

Shao L, Yu X, Feng C (2019) Evaluating the eco-efficiency of China's industrial sectors: A two-stage network data envelopment analysis. Journal of environmental management 247: 551-560.

Shen JM, Zhang XH, Lv YF, Yang XD, Wu J, Lin LL, Zhang YZ (2019) An improved emergy evaluation of the environmental sustainability of China's steel production from 2005 to 2015.Ecological indicators 103:55-69.

Shi Y, Liu J, Shi H, Li H, Li Q (2017) The ecosystem service value as a new eco-efficiency indicator 
for industrial parks. Journal of Cleaner Production 164: 597-605.

Sturm A, Wackernagel M, Muller K (2004) The winners and losers in global competition: Why ecoefficiency reinforces competitiveness: A study of 44 nations. West Lafayette, USA Purdue University Press.

Sun Y, Gao Y (2017) Traffic organization-based layout of function area in logistics park. Journal of Tongji University (Natural Science) 45(3):369-376.

Tian G, Ren Y, Feng Y, Zhou M, Zhang H, Tan J (2019) Modeling and planning for dual-objective selective disassembly using AND/OR graph and discrete artificial bee colony. IEEE Transactions on Industrial Informatics, 15: 2456-2468.

Trochu J, Chaabane A, Ouhimmou M (2020) A carbon-constrained stochastic model for eco-efficient reverse logistics network design under environmental regulations in the CRD industry. Journal of Cleaner Production 245:118818.

Wang C, Liu HJ, Yu LE, Wang HY (2020) Study on the sustainability evaluation method of logistics parks based on emergy 8(10):1247.

Wang Y, Li P, Zhu Z, Liu Z (2019) The evaluation of eco - efficiency of the industrial coupling symbiosis network of the eco - industrial park in oil and gas resource cities. Energy Science \& Engineering 7(3): 899-911.

Wang Y, Xin L (2020) The impact of China's trade with economies participating in the Belt and Road Initiative on the ecological total factor energy efficiency of China's logistics industry. Journal of Cleaner Production 276: 124196.

Wang Z, Han YM, Li CF, Geng ZQ, Fan JZ (2021) Input-Output Networks considering Graphlet-based Analysis for Production Optimization: Application in Ethylene Plants. Journal of Cleaner Production 278: 123955.

Willard B (2002) The Sustainability Advantage Seven Business Case Benefits of a Triple Bottom. Line. Gabriola Island: New Society Publishers.

Xu J, Yang J, Gao C, Zhang L, Ma T (2018) Study on logistics park's radiation scope based on the breaking point model. Transportation Reform and Change - Equity, Inclusiveness, Sharing, and Innovation - Proceedings of the 17th COTA International Conference of Transportation Professionals 2018-January:1440-1446.

Yu S, Liu J, Li H (2020) Evaluating provincial eco-efficiency in China: an improved network data envelopment analysis model with undesirable output. Environmental Science and Pollution Research 27:6886-6903.

Zhai M, Huang G, Liu L, Zheng B, Guan Y (2020) Inter-regional carbon flows embodied in electricity transmission: network simulation for energy-carbon nexus. Renewable and Sustainable Energy Reviews 118: 109511.

Zhang H, You JX, Haiyirete X, Zhang TY (2020) Measuring Logistics Efficiency in China Considering Technology Heterogeneity and Carbon Emission through a Meta-Frontier Model. Sustainability 12(19):8157.

Zhang J, Wang J, Liu T, Han D (2019) Intuitionistic fuzzy measures of enterprise Eco-efficiency and its influencing factors. Journal of Intelligent \& Fuzzy Systems 37(1): 185-192.

Zheng WJ, Xu XH, Wang HW (2020) Regional logistics efficiency and performance in China along the Belt and Road Initiative: The analysis of integrated DEA and hierarchical regression with carbon constraint. Journal of cleaner production 276:123649. 
Figures

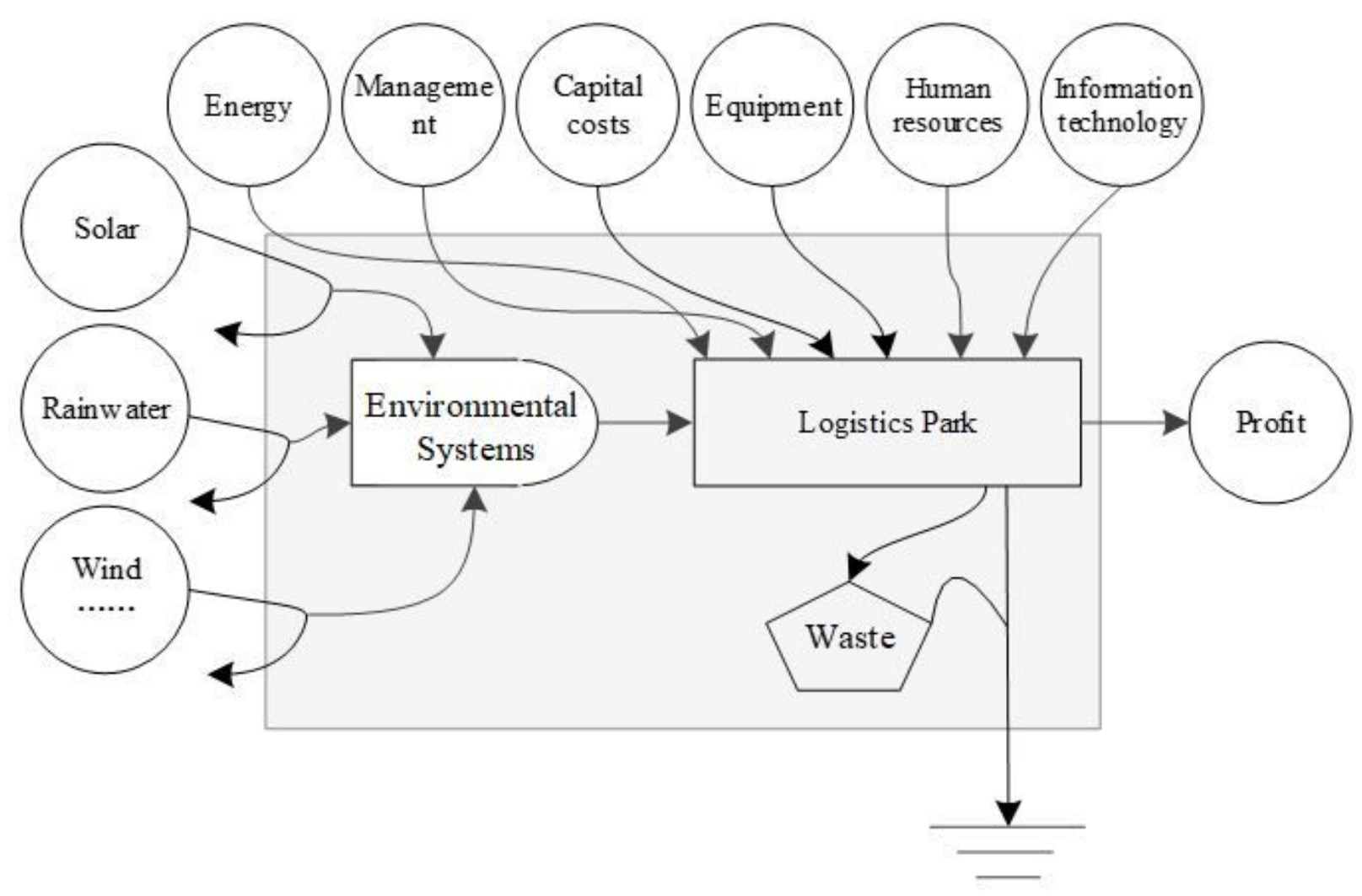

Figure 1

Emergy system diagram of a logistics park. 


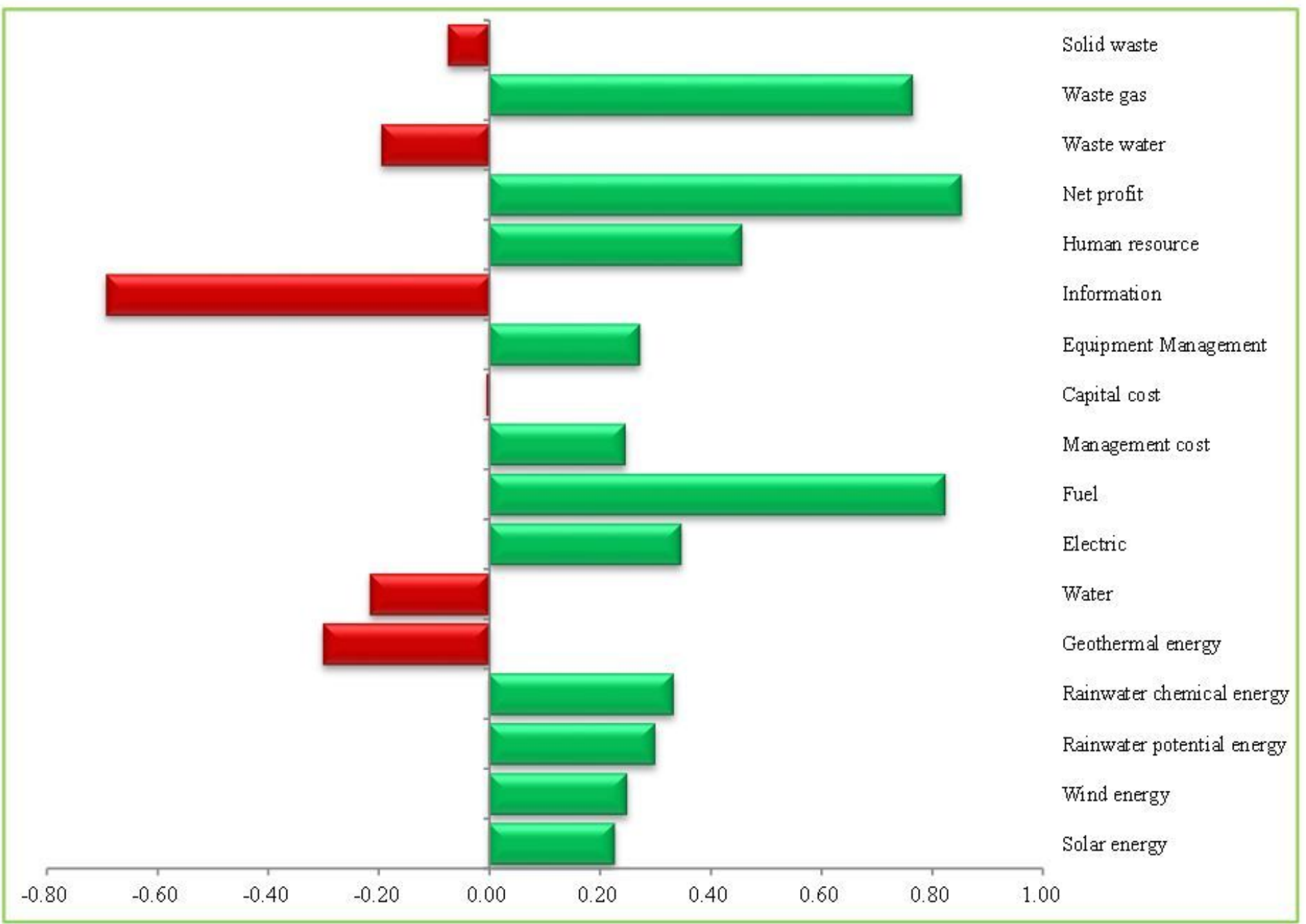

Figure 2

Results of correlation analysis 